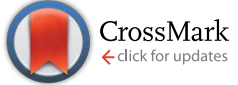

Cite this: RSC Adv., 2016, 6, 16662
Received 26th November 2015 Accepted 29th January 2016

DOI: $10.1039 / c 5 r a 24797 g$

www.rsc.org/advances

\section{Growth mechanism for alternating supply epitaxy: the unique pathway to achieve uniform silicon carbide films on multiple large-diameter silicon substrates}

\author{
Li Wang, ${ }^{\text {*a }}$ Sima Dimitrijev, ${ }^{a}$ Andreas Fissel, ${ }^{\mathrm{b}}$ Glenn Walker, ${ }^{\mathrm{a}}$ Jessica Chai, ${ }^{a}$ \\ Leonie Hold, ${ }^{a}$ Alanna Fernandes, ${ }^{c}$ Nam-Trung Nguyen ${ }^{a}$ and Alan lacopi ${ }^{a}$
}

\begin{abstract}
Low-cost large-diameter cubic silicon carbide (3C-SiC) film grown on silicon ( $\mathrm{Si}$ ) has been demonstrated to have a wide range of applications in photonics, electronics, photoelectrochemistry and micro-electromechanical system technologies. In this paper, the epitaxial growth of SiC on Si by low-pressure chemical vapour deposition is investigated. Two modes were employed to supply the precursors: the alternating supply and the simultaneous supply. Compared with SiC films grown at the same temperature by simultaneous supply epitaxy method, the SiC grown by alternating supply epitaxy (ASE) method has better crystallinity, smoother surface, and better thickness uniformity as confirmed by X-ray diffraction and atomic force microscopy characterisation. We propose the growth mechanism for ASE growth of $3 \mathrm{C}-\mathrm{SiC}$ and validate it in detail experimentally. It is found that, Si deposition on $\mathrm{SiC}$ follows either Stranski-Krastanov mode or island growth mode, while SiC formation proceeds in two possible reaction paths: redistributing of the formed $\mathrm{Si}$ islands or smoothing of the formed $\mathrm{SiC}$ islands by decomposition migration process. Both reaction paths are driven by minimizing the surface free energy and reducing dangling bonds density. In summary, the key features of ASE are: (1) Si has a longer diffusion length and thus higher probability to adhere to a crystallographically favourable position; (2) undesirable gas phase reactions can be avoided. The obtained results indicate that ASE is a unique and economically viable method to prepare uniform 3C-SiC on multiple large-diameter Si wafers.
\end{abstract}

\section{Introduction}

Cubic silicon carbide (3C-SiC) has a unique combination of a wide bandgap, high electron mobility, excellent chemical stability and mechanical properties. More importantly, this material can be epitaxially grown on a large-diameter $\mathrm{Si}$ substrate in a cost-effective manner..$^{1-3}$ Possessing all these features, a wide range of applications using $3 \mathrm{C}-\mathrm{SiC}$ on $\mathrm{Si}$ templates have been demonstrated. Because of the similarity of 3C-SiC(111) to AlN, GaInN, GaN, and graphene in lattice structure and lattice constant, low cost 3C-SiC/Si wafers have been used as a template for GaN growth and graphene preparation., Compared to the more commonly available hexagonal polytypes SiC (bandgap of 3.0-3.2 eV), 3C-SiC has a bandgap of $2.36 \mathrm{eV}$ which enables it to more efficiently absorb the visible light from the solar spectrum, demonstrating itself as a desirable

\footnotetext{
${ }^{a}$ Queensland Micro- and Nanotechnology Centre, Griffith University, Nathan, QLD, 4111, Australia.E-mail: l.wang@griffith.edu.au

${ }^{b}$ Institute of Electronic Materials and Devices, Leibniz University of Hannover, Schneiderberg 32, 30167, Hannover, Germany

${ }^{c}$ Bluglass Ltd., 74 Asquith Street, Silverwater, NSW, 2128, Australia
}

candidate for electrodes for solar water splitting cells applications. ${ }^{6,7}$ The large refractive index difference between $\mathrm{SiC}$ and AlN enabled the fabrication of an AlN/SiC distributed Bragg reflector (DBR) to enhance the light extraction for nitrides deposited on Si substrates. ${ }^{8}$ The high gauge factor of $3 \mathrm{C}-\mathrm{SiC}$ also makes it a good material for fabrication of micro-electromechanical systems (MEMS). ${ }^{9}$ In order to facilitate industry adoption of these technologies, uniform 3C-SiC films must be prepared in large-scale with an economically viable manufacturing method.

Extensive efforts to grow high quality 3C-SiC on largediameter Si substrate have been reported in the literature. Yet, due to the limitations of conventional reactor designs, the quantity of the wafers that can be processed in a single deposition run is limited by the diameter of the susceptor, generally up to six $50 \mathrm{~mm}$ wafers or one $200 \mathrm{~mm}$ wafer. ${ }^{10}$ The custommade low-pressure chemical vapour deposition (LPCVD) reactor used in our investigation has the capacity to produce up to seven $150 \mathrm{~mm}$ Si wafers with excellent thickness uniformity in a single run. A new production model of this LPCVD reactor, named Epiflx, co-developed by SPT Microtechnologies USA, Inc. 
and Griffith University, has demonstrated the ability to deposit $\mathrm{SiC}$ uniformly on $300 \mathrm{~mm}$ Si wafers. ${ }^{11}$

Generally, two different methods were adopted to grow SiC. The most common SiC deposition technique is simultaneous supply epitaxy (SSE),${ }^{12}$ where the deposition is usually performed at either reduced pressure or atmospheric pressure using a chemical vapour deposition (CVD) reactor. The other deposition technique is alternating supply epitaxy (ASE), where Si-containing and C-containing precursors are supplied alternatively. This method can be performed using either a lowpressure CVD reactor or a molecular beam epitaxy reactor. ${ }^{1,3,13}$ ASE method is also known as migration enhanced epitaxy, ${ }^{14-16}$ and has the advantages of reducing deposition temperature, excellent thickness uniformity across large-diameter wafers and precise thickness control., ${ }^{3,17}$ For example, a surface roughness reduction from $28.9 \mathrm{~nm}$ (grown by SSE) to $0.34 \mathrm{~nm}$ was obtained for the growth of AlN by ASE. ${ }^{15}$ Hot wire chemical vapour deposition (HWCVD) can also be used to deposit amorphous and crystalline $\mathrm{SiC}$ at relatively low substrate temperatures $\left(\sim 800{ }^{\circ} \mathrm{C}\right)$. However, the thickness of epitaxially grown $\mathrm{SiC}$ was limited to $50 \mathrm{~nm}$ due to the passivation of the surface by $\mathrm{C}-\mathrm{H}$ bonds. ${ }^{18}$ The lifetime of filament is also an important issue for HWCVD. ${ }^{19}$ High thickness uniformity ( 99\%) 3C-SiC was demonstrated on $150 \mathrm{~mm}$ Si substrates by ASE method at 1000 ${ }^{\circ} \mathrm{C} ., 17$ However, the growth mechanism for the improvement in thickness uniformity with ASE growth was not well understood. This paper proposes the growth mechanism of ASE method based on experimental data. The surface morphology and crystalline quality of grown $\mathrm{SiC}$ on both $\mathrm{Si}(100)$ and $\mathrm{Si}(111)$ substrates are evaluated using atomic force microscopy (AFM), scanning electron microscopy (SEM), and X-ray diffractometry (XRD). The dependence of SiC film quality and morphology on growth methods is discussed.

\section{Experimental details}

The growth of 3C-SiC was performed on both on-axis (off-cut angle $\left.<0.5^{\circ}\right) 150 \mathrm{~mm} \mathrm{Si}(111)$ and $\mathrm{Si}(100)$ substrates (both are p-type doped with resistivity in the range of 1-10 $\Omega \mathrm{cm}$ ) using a custom-made low-pressure chemical vapour deposition reactor (LPCVD) at a temperature of $1000{ }^{\circ} \mathrm{C} . \mathrm{SiH}_{4}(99.9994 \%)$ and $\mathrm{C}_{3} \mathrm{H}_{6}(99.999 \%)$ were used as precursors. After loading the Si wafers into the LPCVD reactor, an in situ surface cleaning procedure was employed to achieve atomically flat fresh $\mathrm{Si}$ surface, ${ }^{20}$ followed by a carbonisation step started at $9500^{\circ} \mathrm{C}$ with $\mathrm{C}_{3} \mathrm{H}_{6}$. The temperature was subsequently ramped up to $1000^{\circ} \mathrm{C}$ with the flowing of $\mathrm{SiH}_{4}$ and $\mathrm{C}_{3} \mathrm{H}_{6}$. Upon reaching the growth temperature, the SiC growth was performed using both SSE and ASE methods. During the SSE growth process, the $\mathrm{C} / \mathrm{Si}$ mole ratio was varied from $2: 1$ to $12: 1$, we achieved the optimum condition [based on the smallest full-width at half-maximum (FWHM) in X-ray diffraction rocking curve (RC) peaks, the most specular surface in optical microscope observation and the smoothest surface in AFM observation] with $8.0 \mathrm{sccm}$ (standard cubic centimetre per minute) $\mathrm{C}_{3} \mathrm{H}_{6}$ to $2.0 \mathrm{sccm} \mathrm{SiH}_{4}$, no dilution/carrier gas was used at any growth stage. ASE growth experiments were performed on $10 \mathrm{~nm} \mathrm{SiC} \mathrm{barrier} \mathrm{layer} \mathrm{grown}$ by SSE method. If an ASE growth was directly performed on the carbonised SiC layer (thickness is $\sim 3 \mathrm{~nm}$ ), dense voids would develop during the pump out steps because the thin $3 \mathrm{~nm} \mathrm{SiC}$ layer is not an effective barrier to restrict the out-diffusion of $\mathrm{Si}$ at the growth temperature of $1000^{\circ} \mathrm{C} .{ }^{1}$ The out diffusion of $\mathrm{Si}$ is prevented during SSE, because of the high Si partial pressure always present during SSE growth. ${ }^{21}$ For SiC grown using the ASE method, the epitaxial growth was also performed by varying flow rates and supply time of $\mathrm{SiH}_{4}$ and $\mathrm{C}_{3} \mathrm{H}_{6}$. We found the optimum $\mathrm{C} / \mathrm{Si}$ ratio in each cycle to be around $4.76: 1$ to $5.58: 1$ with a growth rate of $0.82 \pm 0.03 \mathrm{~nm}$ per cycle. Fig. 1 shows an example of a typical ASE growth cycle with four steps:

(1) Supplying of $\mathrm{SiH}_{4}$ for $60 \mathrm{~s}$ with a flow rate of $1.4 \mathrm{sccm}$; (2) pumping out for $10 \mathrm{~s}$; (3) supplying of $\mathrm{C}_{3} \mathrm{H}_{6}(6.7 \mathrm{sccm})$ for $20 \mathrm{~s}$; (4) pumping out for $10 \mathrm{~s}$.

The thicknesses of grown SiC films were measured by NANOMETRICS NanoSpec/AFT 210 interferometer, assuming a refractive index of 2.65. The thickness uniformity across 150 $\mathrm{mm}$ wafer was evaluated by 5 points measurements with 10 $\mathrm{mm}$ edge exclusion. AFM measurements were performed using Park NX20 under non-contact mode. XRD measurements were performed with a PANalytical Empyrean X-ray diffractometer using $\mathrm{Cu} \mathrm{K} \alpha 1$ radiation $(\lambda=1.5405980 \AA)$. It has a high resolution four-crystal $\mathrm{Ge}(220)$ asymmetrical incident beam monochromator and a PIXcel-3D detector with a fixed anti-scatter slit. The PIXcel detector was used in the Open Detector (OD) mode for the rocking curve (RC) measurements. SEM (model: JSM-6510LV from JEOL) top-view images were taken at an operating voltage of $15 \mathrm{kV}$ with a working distance of $15 \mathrm{~mm}$.

\section{Results and discussion}

\section{Comparison between ASE and SSE}

$\mathrm{SiC}$ growth was performed on both $\mathrm{Si}(111)$ and $\mathrm{Si}(100)$ substrates using optimized SSE and ASE methods at $1000{ }^{\circ} \mathrm{C}$ to investigate the growth mechanisms and film quality. The thickness of the SiC film was controlled at $240 \pm 5 \mathrm{~nm}$. The thickness uniformity, the root-mean-square (RMS) roughness, and the FWHM from RC scans are shown in Table 1.

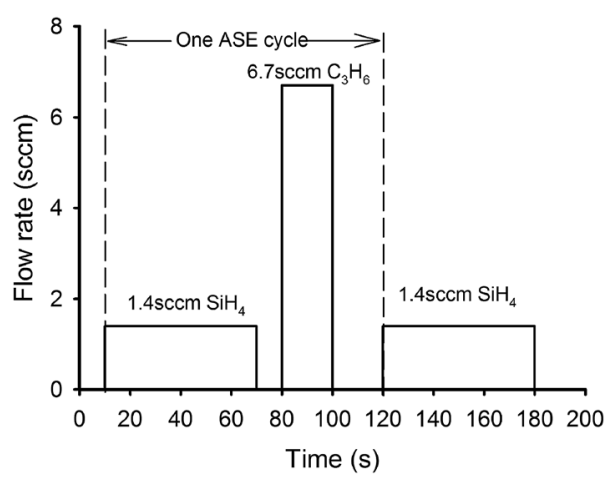

Fig. 1 An illustrative example of an ASE growth cycle, one cycle is composed of four steps: supplying of $\mathrm{SiH}_{4} \rightarrow$ pumping out $\rightarrow$ supplying of $\mathrm{C}_{3} \mathrm{H}_{6} \rightarrow$ pumping out. 
Table 1 Properties of SiC films grown by SSE and ASE methods at $1000^{\circ} \mathrm{C}$

\begin{tabular}{llll}
\hline & $\begin{array}{l}\text { Thickness uniformity } \\
\text { across } 150 \mathrm{~mm} \text { wafer }(\%)\end{array}$ & $\begin{array}{l}\text { RMS roughness in } \\
\text { a scan area of } 1 \mu \mathrm{m} \times 1 \mu \mathrm{m}(\mathrm{nm})\end{array}$ & $\begin{array}{l}\text { FWHM of rocking curve } \\
\text { scan of SiC }(111) /(100) \text { peak }\left({ }^{\circ}\right)\end{array}$ \\
\hline SiC_SSE_111 & $93.6 \pm 0.5$ & $4.5 \pm 0.2$ & $1.62 \pm 0.05$ \\
SiC_ASE_111 & $99.3 \pm 0.3$ & $3.2 \pm 0.2$ & $1.28 \pm 0.05$ \\
SiC_SSE_100 & $92.9 \pm 0.3$ & $5.3 \pm 0.2$ & $1.41 \pm 0.05$ \\
SiC_ASE_100 & $99.2 \pm 0.5$ & $4.4 \pm 0.2$ & $1.04 \pm 0.05$
\end{tabular}

For $240 \pm 5 \mathrm{~nm} \mathrm{SiC}$, an excellent thickness uniformity of around $99.3 \%$ was achieved using ASE method on both $\operatorname{Si}(111)$ and $\mathrm{Si}(100)$ substrates, whereas a poorer uniformity of $\sim 93.3 \%$ was observed for films grown by SSE method. Furthermore, much narrower FWHM from XRD RC measurement was obtained for SiC grown by ASE method, with a reduction of 14.8 and $26.2 \%$ for (111) and (100) orientation compared to SSE method, respectively. Switching the growth method from SSE to ASE at $1000{ }^{\circ} \mathrm{C}$ also enabled a reduction in SiC RMS roughness for both orientations.

Fig. 2 shows the top-view AFM images of these films. The surface of both $\mathrm{SiC}(111)$ and $\mathrm{SiC}(100)$ grown by SSE is quite rough with round granular feature [shown in Fig. 2(a) and (c)], indicating the dominant growth mode is the random formation of three-dimensional islands and/or Stranski-Krastanov (SK) mode. For a scan area of $1 \mu \mathrm{m} \times 1 \mu \mathrm{m}$, the recorded RMS roughness is $4.5 \pm 0.2$ and $5.3 \pm 0.2 \mathrm{~nm}$ for the samples SiC_SSE_111 and SiC_SSE_100, respectively. Comparatively, triangular features for the sample SiC_ASE_111 [Fig. 2(b)] and square/rectangular features for the sample SiC_ASE_100 [Fig. 2(d)] were seen in the film grown by ASE method, in good agreement with the substrate surface rotation symmetry. The SiC film grown on (111) substrate (RMS $=3.2 \pm 0.2 \mathrm{~nm}$ ) is smoother than that grown on (100) substrate (RMS $=4.4 \pm 0.2 \mathrm{~nm})$, although the $\mathrm{SiC}(100)$ film has a better crystalline quality as demonstrated by a narrower FWHM value (Table 1). The resulting inferior crystalline quality (a)

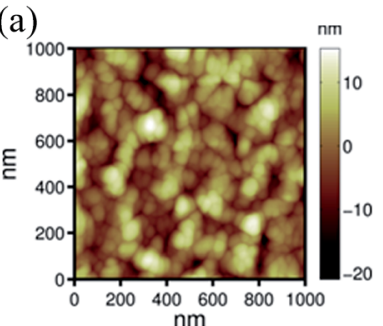

(c)

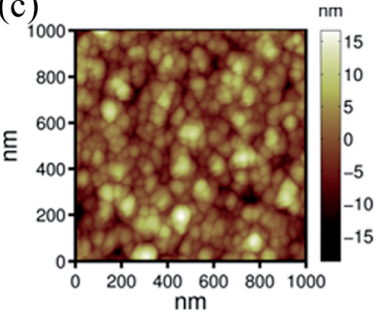

(b)

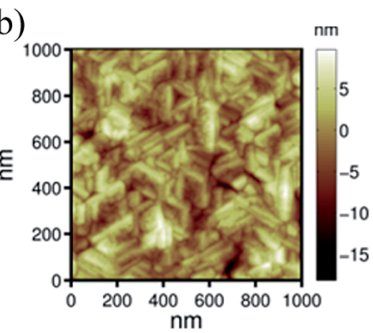

(d)

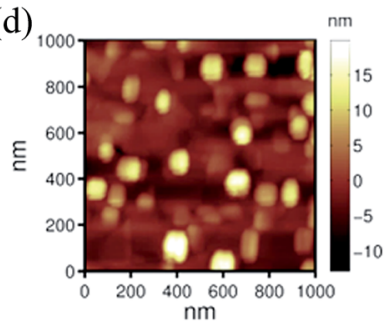

Fig. 2 The top-view AFM images of $240 \pm 5 \mathrm{~nm} \mathrm{SiC(111)} \mathrm{and} \mathrm{SiC}(100)$ film grown by (a) SiC_SSE_111, RMS $=4.5 \pm 0.2 \mathrm{~nm}$, (b) SiC_ASE_111, $\mathrm{RMS}=3.2 \pm 0.2 \mathrm{~nm}$, (c) SiC_SSE_100, RMS $=5.3 \pm 0.2 \mathrm{~nm}$, and (d) SiC_ASE_100, RMS $=4.4 \pm 0.2 \mathrm{~nm}$. Scan area is $1 \mu \mathrm{m} \times 1 \mu \mathrm{m}$. and larger surface roughness during the SSE growth at a temperature of $1000{ }^{\circ} \mathrm{C}$ can be interpreted in terms of limited adatom diffusion length, unavoidable gas-phase reaction, and relatively higher arrival rate of growth species. In contrast, by separating/alternating the supply of $\mathrm{SiH}_{4}$ and $\mathrm{C}_{3} \mathrm{H}_{6}$ in the ASE method, undesirable gas-phase reactions can be avoided, leading to an improvement in SiC crystallinity.

\section{The growth mechanism of ASE}

Fig. 3 illustrates the proposed growth models. This hypothesis is tested by experiments, which interprets how the SiC growth proceeds.

(a)

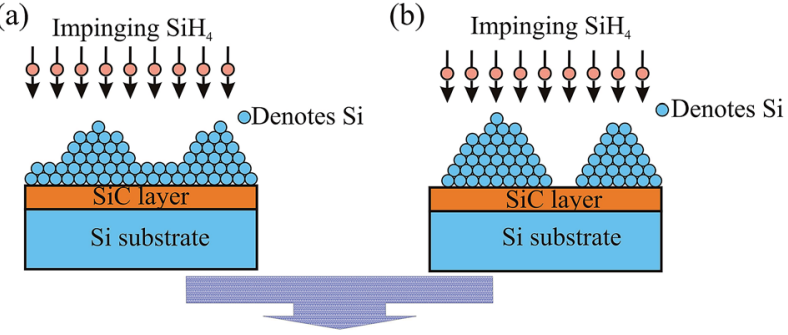

(c) Impinging $\mathrm{C}_{3} \mathrm{H}_{6}$

(d) Impinging $\mathrm{C}_{3} \mathrm{H}_{6}$

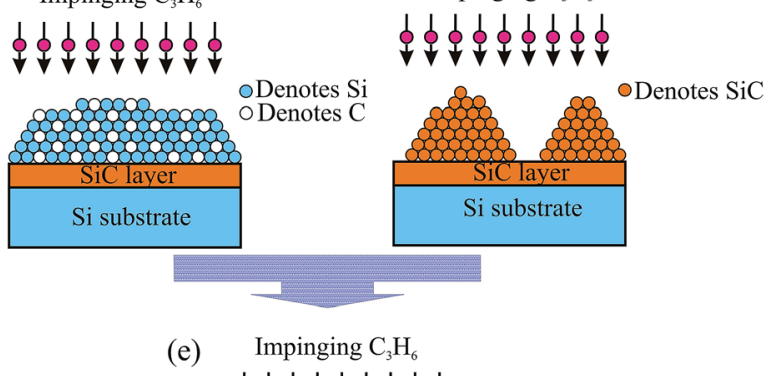

oDenotes $\mathrm{SiC}$

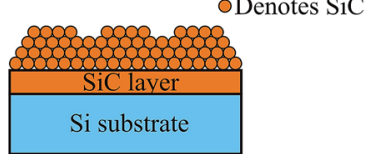

Fig. 3 The proposed growth models for 3C-SiC growth using ASE method. Si growth on SiC template can proceed in both SK mode, shown in (a), and in island mode as shown in (b) with the supply of $\mathrm{SiH}_{4}$ gas. The formation of smooth $\mathrm{SiC}$ layers can then proceed in two possible pathways. One reaction path is following what is proposed in (c) where the initial carbon diffusion in Si leads to a carbon-assisted $\mathrm{Si}$ redistribution, and the smoothed Si layers are subsequently converted into smooth $\mathrm{SiC}$ layer as shown in (e). The other reaction path commences with the formation of $\mathrm{SiC}$ islands, shown in (d), followed by subsequent self-flattening effect driven by reducing total surface free energy and dangling bonds density, leading to the formation of smooth SiC layers (e). 
Each ASE growth cycle started with a $\mathrm{SiH}_{4}$ supply step, where the $\mathrm{SiH}_{4}$ flow rate was controlled below $3 \mathrm{sccm}$ and the chamber pressure was controlled less than $0.05 \mathrm{~Pa}$ (the calculated Knudsen number is $K_{\mathrm{n}}=2.5$ ), which falls in a transition region from pure laminar flow to pure molecular flow. Therefore, the growth is possibly mainly governed by surface diffusion rather than by the transport of the precursors through the boundary layer towards the surface. As a result, excellent thickness uniformity within the wafer was obtained. Due to the large lattice mismatch of $\sim 20 \%$ between $\mathrm{Si}$ and SiC and high mobility of $\mathrm{Si}$ on $\mathrm{SiC},{ }^{22} \mathrm{Si}$ deposition on $\mathrm{SiC} / \mathrm{Si}$ template follows $\mathrm{SK}$ growth mode as shown in Fig. 3(a) (when the adsorbed third layer of atoms have different bonding properties compared to the first and second layers of adatoms ${ }^{16,23}$ ) or islands growth mode as shown in Fig. 3(b). In both cases, Si islands are formed on top of $\mathrm{SiC} / \mathrm{Si}$ template. In the proposed growth model, the presence or absence of smooth wetting layers underneath the formed Si islands is irrelevant, as the smooth wetting layers will neither contribute to the increase in the final SiC roughness, nor impact the rationale used in the proposed growth models. A short pumping out step was adopted after $\mathrm{SiH}_{4}$ flow to avoid mixing of $\mathrm{SiH}_{4}$ and $\mathrm{C}_{3} \mathrm{H}_{6}$. It is very likely that $\mathrm{Si}$ atoms keep repositioning themselves during this pumping step. The formation of smooth SiC layers can then proceed in two possible pathways. One reaction path is following what is proposed in Fig. 3(c) where the initial carbon diffusion in Si leads to a carbon-assisted Si redistribution, and the smoothed Si layers are subsequently converted into smooth SiC layer, Fig. 3(e). This can be explained by the fact, that covering of $\mathrm{SiC}$ by $\mathrm{Si}$ is preferred energetically and in case of bonding saturation, usually less volatile carbon initially occupies only weakly-bound surface states. That means, the reaction of $\mathrm{Si}$ and $\mathrm{C}$ could be initially suppressed because of the high surface energy and the low heat of SiC formation. ${ }^{24}$ In this way the carbon atoms become more mobile and can move to low energy sites resulting in a layer-by-layer growth mode. Moreover, the activation energy for the formation of critical SiC-nucleus may be increased by the exchange of silicon and carbon. Therefore, SiC formation always should occur below Si layer. On the other hand, the formation of $\mathrm{SiC}$ islands at the first instant of $\mathrm{C}_{3} \mathrm{H}_{6}$ supply cannot be excluded as illustrated in Fig. 3(d), because carbon has a fast diffusion rate in Si: it diffuses $10 \mathrm{~nm}$ in less than 3 seconds. ${ }^{25}$ The formed $\mathrm{SiC}$ islands are then converted into smooth layers as shown in Fig. 3(e) due to a slowly recovery/ decomposition migration process, also aiming at minimizing the surface free energy by smoothing the surface and reducing dangling bonds density. The self-flattening effect has been previously reported for the growth of GaAs using alternate supply method. ${ }^{16}$ Because the supplied Si atoms and $\mathrm{C}$ atoms are not exact the integer numbers of monolayer $(\mathrm{ML})$, atomic steps do exist in the grown $\mathrm{SiC}$ layers and result in the accumulation of roughness with the increase of growth cycles.

To test the above hypothesis, a single step Si deposition experiment was performed on both $\mathrm{SiC}(111) / \operatorname{Si}(111)$ and $\mathrm{SiC}(100) / \mathrm{Si}(100)$ templates, using the same $\mathrm{SiH}_{4}$ flow rate as it is applied in a single ASE cycle. The surfaces were then investigated using both SEM and AFM. However, no distinguishable islands were visible. The surface morphology and roughness are just identical to that of the original template surfaces prior to $\mathrm{Si}$ deposition, as shown in Fig. 2(b) and (d). These results indicated that the Si deposition happens either in two-dimensional (2D) mode or in SK/islands mode, but the islands are not observable if their size is comparable to the size of surface features. The $10 \mathrm{~nm}$ thick SiC barrier layer has a peak-to-valley value of $\sim 6 \mathrm{~nm}$ and a lateral domain dimension of $\sim 25 \pm 5 \mathrm{~nm}$ (AFM top-view images are shown in Fig. 4(a) for (111) orientation and Fig. 4(b) for (100) orientation). If the Si deposition occurs in 2D mode only, and no additional roughening process is introduced during the carbonisation step, then the surface roughness is expected to remain constant with increasing film thickness. However, a continuous increase of roughness with film thickness was previously observed for the SiC films, ${ }^{1}$ indicating that Si growth occurs in SK and/or islands mode rather than layer-by-layer growth mode.

To gain more information on the growth behaviour of $\mathrm{Si}$ on SiC, Si deposition was also performed using the same flow rate of $\mathrm{SiH}_{4}$ but with a longer supply time. When the amount of deposited Si is doubled, distinct Si islands with lateral size of $\sim 500 \mathrm{~nm}$ (height up to $120 \mathrm{~nm}$ ) were seen on the surfaces of SiC/Si(111) and SiC/Si(100) by AFM, shown in Fig. 5(a) and (b). A higher nucleation density was observed on (100) orientation, demonstrating that Si growth predominantly follows islands growth mode. After a $60 \mathrm{~min} \mathrm{Si}$ deposition, larger three dimensional Si islands were observed on both 3C-SiC(111)/ $\operatorname{Si}(111)$ [nucleation density of $8.5 \times 10^{6} \mathrm{~cm}^{-2}$ shown in Fig. 5(c)] and 3C-SiC(100)/Si(100) [nucleation density of $1.9 \times$ $10^{7} \mathrm{~cm}^{-2}$ shown in Fig. 5(d)] templates, which again confirms that $\mathrm{Si}$ growth goes predominantly in island growth mode with extended Si supply. Therefore, the rather small change in island density accompanied by a corresponding increase in island size indicate that Oswald's ripening process contributes only marginal to the formation of larger flat Si islands. The average nearest distance between $\mathrm{Si}$ islands is around $2 \mu \mathrm{m}$, indicating a diffusion length in the range of $1 \mu \mathrm{m}$ for Si on SiC surface. Experimental evidence has been previously reported for the formation of Si islands on $\mathrm{SiC},,^{3,22,24,26,27}$ in good agreement with what was found here.

The images shown in Fig. 5 demonstrate that Si islands with lateral size of approximately $500 \mathrm{~nm}$ and a height of up to 120 (a)

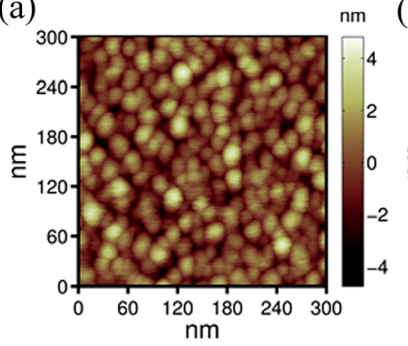

(b)

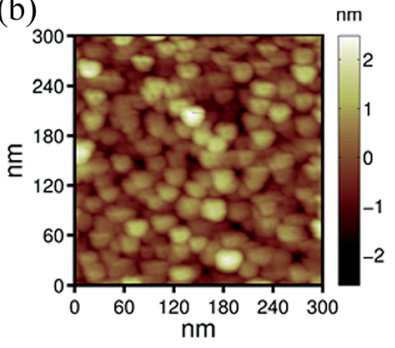

Fig. 4 AFM images of $10 \mathrm{~nm} \mathrm{SiC}$ barrier layer grown on (a) Si(111) and (b) Si(100) using SSE method. Scan area is $0.3 \mu \mathrm{m} \times 0.3 \mu \mathrm{m}$. The aim is to stop the out-diffusion of $\mathrm{Si}$ from the Si substrate. The individual domain has an average lateral size of $25 \pm 5 \mathrm{~nm}$. 
(a)
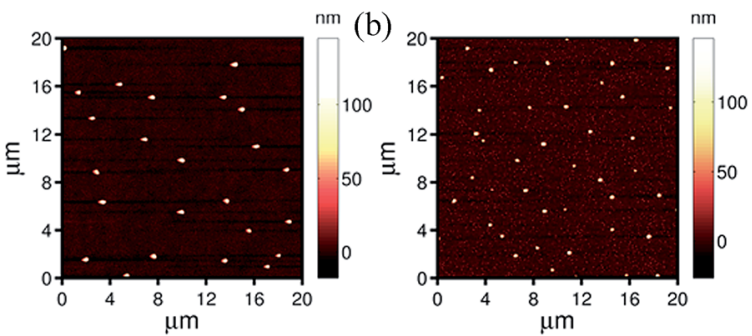

(c)
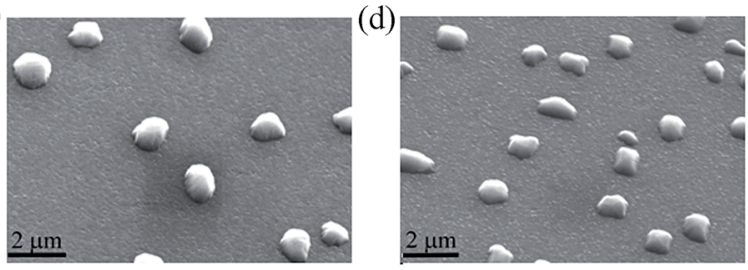

Fig. $5 \mathrm{Si}$ islands formed on the surface with extended $\mathrm{SiH}_{4}$ supply time (a) AFM image of three dimensional $\mathrm{Si}$ islands deposited on $\mathrm{SiC} / \mathrm{Si}(111)$ template with 2 min supply of $1.4 \mathrm{sccm} \mathrm{SiH}_{4}$, island density is $6.0 \times 10^{6}$ $\mathrm{cm}^{-2}$, (b) AFM image of three dimensional Si islands deposited on $\mathrm{SiC} /$ $\mathrm{Si}(100)$ template with 2 min supply of $1.4 \mathrm{sccm} \mathrm{SiH}{ }_{4}$, island density is 1.1 $\times 10^{7} \mathrm{~cm}^{-2}$, (c) SEM image of three dimensional Si islands deposited on $\mathrm{SiC} / \mathrm{Si}(111)$ template with 60 min supply of $1.4 \mathrm{sccm} \mathrm{SiH}_{4}$, island density is $8.5 \times 10^{6} \mathrm{~cm}^{-2}$, and (d) SEM image of three dimensional Si islands deposited on $\mathrm{SiC} / \mathrm{Si}(100)$ template with 60 min supply of $1.4 \mathrm{sccm}$ $\mathrm{SiH}_{4}$, island density is of $1.9 \times 10^{7} \mathrm{~cm}^{-2}$. The island density and size both increased with extended growth time independent of substrate orientation, although the nucleation density is higher on (100) than on (111) orientation.

$\mathrm{nm}$ were formed on surface during 2 min supply of $1.4 \mathrm{sccm}$ $\mathrm{SiH}_{4}$, smooth SiC surface without islands should be obtainable if $\mathrm{C}_{3} \mathrm{H}_{6}$ is able to covert the $\mathrm{Si}$ islands into smooth SiC layers. To confirm this, in an additional experiment, a 250 cycles ASE growth of SiC using the following four steps in each cycle was performed: (1) a two minute supply of $1.4 \mathrm{sccm} \mathrm{SiH}_{4}$ (2) a pump out step of $10 \mathrm{~s}$, (3) a supply of $6.7 \mathrm{sccm}_{3} \mathrm{H}_{6}$ for $40 \mathrm{~s}$, and (4) a pump out step of $10 \mathrm{~s}$. After this growth procedure, no islands were seen on the grown SiC film as observed with different techniques, including optical microscope (OM), SEM and AFM (Fig. 6). If the initially deposited Si islands and formed SiC do not migrate on surface during the ASE growth cycles, then the grown $\mathrm{SiC}$ is expected to possess the similar island morphology
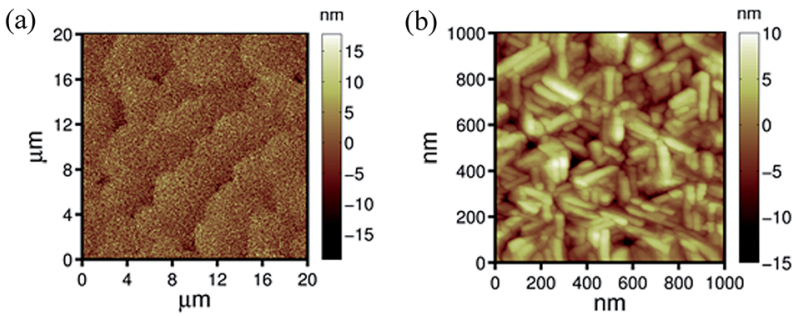

Fig. 6 AFM images of $\sim 250 \mathrm{~nm} \mathrm{SiC}(111)$ film grown on Si(111) substrate, (a) a scan area of $20 \mu \mathrm{m} \times 20 \mu \mathrm{m}$, compared with Fig. 5(a), no islands are observed, indicating that $\mathrm{Si}$ islands are re-distributed by the presence of $\mathrm{C}_{3} \mathrm{H}_{6}$ during $\mathrm{SiC}$ growth; and (b) a scan area of $1 \mu \mathrm{m} \times$ $1 \mu \mathrm{m}$, the RMS roughness is $3.2 \pm 0.2 \mathrm{~nm}$, similar to what was reported in Fig. 2(a) for SiC film grown with slower growth rate. as previously deposited $\mathrm{Si}$ islands. However, the $\mathrm{Si}$ islands visible in Fig. 5 are clearly absent on the final SiC film as shown in Fig. 6(a) in the same scan area of $20 \mu \mathrm{m} \times 20 \mu \mathrm{m}$, which demonstrates that $\mathrm{Si}$ islands are re-distributed by the presence of $\mathrm{C}_{3} \mathrm{H}_{6}$. The surface morphology shown in Fig. 6(b) is similar to what shown in Fig. 2(b) with a similar RMS roughness at $3.2 \pm$ $0.2 \mathrm{~nm}$, where the $\mathrm{SiC}$ film has similar thicknesses of $\sim 250 \mathrm{~nm}$. However, the XRD evaluation indicated degradation in crystalline quality. The FWHM from RC measurements is $1.48 \pm 0.05^{\circ}$,

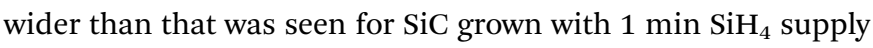
$\left(\right.$ FWHM $\left.=1.28 \pm 0.05^{\circ}\right)$, suggesting that, even though the $\mathrm{Si}$ islands can be re-distributed, the larger and denser $\mathrm{Si}$ islands lead to a growth of inferior quality SiC. The highest quality SiC shall be obtained with minimum extra Si islands formation during the $\mathrm{SiH}_{4}$ supply step. However, Si deposition without island formation on $\mathrm{SiC}$ is difficult to achieve due to the absence of self-limiting mechanism in CVD growth, extra Si layers adsorption have been previously reported by other research groups. ${ }^{3,27}$ Only at very low $\mathrm{Si}$ deposition rates in the range of $0.01 \mathrm{ML} \mathrm{s}^{-1}$ to $0.05 \mathrm{ML} \mathrm{s}^{-1}$, Si island formation was prevented in molecular beam epitaxy at temperature in the range between $850{ }^{\circ} \mathrm{C}$ and $1000{ }^{\circ} \mathrm{C}^{24}$ The smooth Si layer in this case results from the reduced adsorption on the SiC surface covered by a Sirich $(3 \times 3)$ surface supersaturation. Further Si deposition results in the growth of highly strained layers and strained $\mathrm{Si}$ exhibits larger equilibrium vapour pressure. In literature, the absence of self-limiting mechanism was also reported for the growth of GaAs using ASE method, ${ }^{16}$ where high quality and smoother film can be obtained by confining the Ga flux to be equal to one or two ML. If Ga flux was over $2 \mathrm{ML}$, surface roughness would increase accordingly. This indicated that high quality SiC might be achieved when the growth rate is limited to $1 \mathrm{ML}$ or $2 \mathrm{ML}$ per cycle, which will be investigated in future.

The key features of alternating supply epitaxy are: (1) Si has a longer diffusion length (compared with $\mathrm{SiC}$ ) on SiC surface and thus higher probability to adhere to a crystallographically favourable position, which enhanced the proportion of twodimensional growth; (2) undesirable gas phase formation of $\mathrm{SiC}$ is avoided. As a result, ASE growth technique has several advantages over SSE at the growth temperature of $1000{ }^{\circ} \mathrm{C}$ : excellent thickness uniformity, smoother surface and better crystallinity. The suitability of this method to prepare SiC/AlN DBR had been successfully demonstrated, ${ }^{8}$ as it leads to a deposition of uniform SiC layer with precise thickness control within $\pm 1 \mathrm{~nm}$. By enhancing the mobility of surface adatoms, step-flow controlled $\mathrm{SiC}$ growth was achieved at $1200{ }^{\circ} \mathrm{C}$ on offaxis Si substrate using alternating supply epitaxy method, ${ }^{2}$ the crystallinity of grown $\operatorname{SiC}(111)(\sim 1100 \mathrm{~nm})$ has been greatly improved as indicated by a reduction of $\sim 35 \pm 5 \%$ in RC FWHM value. Although ASE has different growth mechanism compared with SSE, enhanced surface diffusion is beneficial for both growth methods.

\section{Conclusions}

SiC film was hetero-epitaxially grown on both $150 \mathrm{~mm} \mathrm{Si(111)}$ and $\operatorname{Si}(100)$ substrates using custom-made hot wall LPCVD 
reactor at $1000{ }^{\circ} \mathrm{C}$. Compared with simultaneous supply epitaxy method, alternating supply epitaxy method enables the grown SiC film to have much better thickness uniformity, smoother surface and improved crystallinity. The growth mechanism for ASE growth of $3 \mathrm{C}-\mathrm{SiC}$ is proposed. Si islands develop on $\mathrm{SiC} / \mathrm{Si}$ template via a SK and/or islands growth mode during the supply of $\mathrm{SiH}_{4}$ step. These formed Si islands are converted into smooth SiC layers via two possible reaction paths: redistributing the formed Si islands or smoothing the formed SiC islands by decomposition migration process. Both reaction paths are driven by minimizing the surface free energy and reducing dangling bonds density. The ASE method utilizes the relative longer diffusion length of Si on SiC surface $(\sim 1 \mu \mathrm{m})$ and avoids the gas phase formation of SiC. As a result, smooth SiC layers are formed uniformly cycle by cycle across the large diameter wafers.

\section{Acknowledgements}

The SiC deposition, performed at Queensland Microtechnology Facility, Griffith University, Australia, was funded by SPTS Technologies, Research Partnerships Program Grant titled "Semiconductor Microfabrication Program" (Queensland Government, Australia), and linkage grant (LP150100153) from Australian Research Council. This work was performed in part at the Queensland Node of the Australian National Fabrication Facility, a company established under the National Collaborative Research Infrastructure Strategy to provide nano and microfabrication facilities for Australia's researchers. The high resolution XRD measurements were performed at Bluglass Ltd. Australia.

\section{References}

1 L. Wang, A. Iacopi, S. Dimitrijev, G. Walker, A. Fernandes, L. Hold and J. Chai, Thin Solid Films, 2014, 564, 39-44.

2 L. Wang, G. Walker, J. Chai, A. Iacopi, A. Fernandes and S. Dimitrijev, Sci. Rep., 2015, 5, 15423.

3 H. Nagasawa and K. Yagi, Phys. Status Solidi B, 1997, 202, 335-358.

4 Y. Cordier, E. Frayssinet, M. Portail, M. Zielinski, T. Chassagne, M. Korytov, A. Courville, S. Roy, M. Nemoz, M. Chmielowska, P. Vennéguès, H. P. D. Schenk, M. Kennard, A. Bavard and D. Rondi, J. Cryst. Growth, 2014, 398, 23-32.

5 V. Y. Aristov, G. Urbanik, K. Kummer, D. V. Vyalikh,

O. V. Molodtsova, A. B. Preobrajenski, A. A. Zakharov,

C. Hess, T. Hänke, B. Büchner, I. Vobornik, J. Fujii,
G. Panaccione, Y. A. Ossipyan and M. Knupfer, Nano Lett., 2010, 10, 992-995.

6 N. Ichikawa, M. Kato and M. Ichimura, Appl. Phys. Express, 2015, 8, 091301.

7 Y. Wang, S. Li, J. Han, W. Wen, H. Wang, S. Dimitrijev and S. Zhang, RSC Adv., 2014, 4, 54441-54446.

8 D. Massoubre, L. Wang, L. Hold, A. Fernandes, J. Chai, S. Dimitrijev and A. Iacopi, Sci. Rep., 2015, 5, 17026.

9 H. P. Phan, D. V. Dao, P. Tanner, L. Wang, N. T. Nguyen, Y. Zhu and S. Dimitrijev, Appl. Phys. Lett., 2014, 104, 111905.

10 A. Severino, presented in part at MRS Spring Meeting, San Francisco, April, 2012.

11 D. Massoubre, l. Wang, J. Chai, G. Walker, L. Hold, M. Lobino, S. Dimitrijev and A. Iacopi, Nanotechnol. 2014: Graphene, CNTs, Part., Films Compos., Tech. Proc. NSTI Nanotechnol. Conf. Expo, 2014, 2, 416-419.

12 S. Nishino, J. A. Powell and H. A. Will, Appl. Phys. Lett., 1983, 42, 460.

13 T. Yoshinobu, H. Mitsui, Y. Tarui, T. Fuyuki and H. Matsunami, J. Appl. Phys., 1992, 72, 2006-2013.

14 R. G. Banal, M. Funato and Y. Kawakami, Appl. Phys. Lett., 2008, 92, 241905.

15 F. Yan, M. Tsukihara, A. Nakamura, T. Yadani, T. Fukumoto, Y. Naoi and S. Sakai, Jpn. J. Appl. Phys., 2004, 43, L1057L1059.

16 Y. Horikoshi, M. Kawashima and H. Yamaguchi, Jpn. J. Appl. Phys., Part 1, 1988, 27, 169-179.

17 L. Wang, S. Dimitrijev, J. S. Han, A. Iacopi, L. Hold, P. Tanner and H. B. Harrison, Thin Solid Films, 2011, 519, 6443-6446.

18 K. Yasui, J. Eto, Y. Narita, M. Takata and T. Akahane, Jpn. J. Appl. Phys., Part 1, 2005, 44, 1361-1364.

19 R. E. I. Schropp, Thin Solid Films, 2009, 517, 3415-3419.

20 L. Wang, S. Dimitrijev, A. Iacopi, L. Hold, G. Walker, J. Chai and D. Massoubre, Mater. Sci. Forum, 2015, 821-823, 205208.

21 G. Ferro, Crit. Rev. Solid State Mater. Sci., 2014, 40, 56-76.

22 A. Fissel, K. Pfennighaus and W. Richter, Appl. Phys. Lett., 1997, 71, 2981.

23 W. Seifert, N. Carlsson, M. Miller, M.-E. Pistol, L. Samuelson and L. R. Wallenberg, Prog. Cryst. Growth Charact., 1996, 33, 423-471.

24 A. Fissel, Phys. Rep., 2003, 379, 149-255.

25 C. D. Stinespring and J. C. Wormhoudt, J. Appl. Phys., 1989, 65, 1733.

26 M. Portail, S. Vézian, M. Teisseire, A. Michon, T. Chassagne and M. Zielinski, J. Cryst. Growth, 2014, 404, 157-163.

27 T. Fuyuki, T. Yoshinobu and H. Matsunami, Thin Solid Films, 1993, 225, 225-229. 